\title{
Understanding the causes of overcrowding in emergency departments in the Capital Health Region in Alberta: a focus group study
}

\author{
Angela Estey, MA, BN;* Kathleen Ness, RD, MPH;* L. Duncan Saunders, MB BCh, PhD; $\dagger$ \\ Arif Alibhai, BSc, MHSA; $\dagger$ Robert A. Bear, MD $\ddagger$
}

See also page 81

\begin{abstract}
Objectives: To determine the perceptions of health care professionals and service providers with regard to emergency department (ED) overcrowding, including definitions of overcrowding, characteristics of an overcrowded ED, and causes of overcrowding, and secondarily to solicit potential solutions to the problem.

Methods: Focus groups were conducted with front-line staff, physicians and managers from 7 EDs within an integrated health region. Participants received questions before the sessions, and an experienced moderator conducted the sessions and prepared transcripts from audio tapes. Analyses included identification of key themes and the interrelationships between those themes.

Results: Focus group participants defined service pressures that result in overcrowding as "anything that impedes the flow of patients through the ED, affects the quality of care delivered or results in patient frustration and stress to staff." Overcrowding, which can occur at any time of the day, was perceived to have many causes, including some seasonal factors. Two key problems were identified as causing many spin-off pressures: inefficient access to ED beds (stretchers) because of slow throughput of patients and staff shortages. Other perceived causes included the changing role and use of EDs and limited access to services such as home care, diagnostic imaging, laboratory services, social services and specialist care. Participants generally believed that the characteristics and causes of overcrowding could not be viewed independently; rather, in the search for remedies, they should be considered as interrelated variables.

Conclusion: Qualitative studies of this complex issue can identify and describe complex interactions in real-world settings. The findings of such studies can lead to quantitative studies involving objective measurement.
\end{abstract}

Key words: overcrowding, qualitative studies, emergency bed shortages, staff shortages, emergency department role

\section{RÉSUMÉ}

Objectifs : Déterminer la perception des professionnels de la santé et des dispensateurs de soins de l'encombrement d'un département d'urgence, incluant leur définition de l'encombrement, les caractéristiques et les causes d'une urgence encombrée, et leur demander ensuite de proposer des solutions au problème.

Méthodes : Des groupes de travail composés de personnel de première ligne, de médecins et de gestionnaires provenant de sept départements d'urgence au sein d'une région socio-sanitaire intégrée furent formés. Les participants reçurent les questions avant les séances animées par un

*Clinical Performance, Information and Research, Capital Health Authority, Edmonton, Alta.; †Department of Public Health Sciences, University of Alberta, Edmonton, Alta.; ¥Vice Dean, Faculty of Medicine and Dentistry, University of Alberta, Edmonton, Alta.

Received: Nov. 20, 2002; final submission: Jan. 17, 2003; accepted: Jan. 20, 2003

This article has been peer reviewed. 
modérateur qui s'occupa de la transcription à partir de bandes audio. Les analyses comprenaient l'identification des thèmes clés et les corrélations entre ces thèmes.

Résultats : Les participants du groupe de travail définirent les pressions résultant de l'encombrement comme «tout ce qui perturbe le débit des patients à l'urgence, affecte la qualité des soins donnés ou provoque la frustration des patients et cause du stress chez le personnel.» On attribuait plusieurs causes à l'encombrement, qui peut se produire à n'importe quel moment de la journée, notamment des facteurs saisonniers. Deux problèmes clés furent identifiés comme étant la cause de plusieurs contraintes secondaires : un accès inadéquat aux lits à l'urgence (civières) en raison d'un ralentissement du débit des patients et une pénurie de personnel. Parmi les autres causes soulevées, mentionnons les changements du point de vue du rôle et de l'utilisation de l'urgence et l'accès limité aux services comme les soins à domicile, l'imagerie diagnostique, les services de laboratoire, les services sociaux et les soins des spécialistes. La majorité des participants croyaient que les caractéristiques et les causes de l'encombrement ne pouvaient pas être considérées individuellement, mais plutôt comme des variables en corrélation dans le cadre de la recherche de solutions.

Conclusions : Des études qualitatives de ce problème complexe peuvent permettre d'identifier et de décrire des interactions complexes dans des environnements réels. Les constatations découlant de ces études peuvent mener à des études quantitatives fondées sur des mesures objectives.

\section{Introduction}

In recent years, overcrowding in hospital emergency departments (EDs) has become a major focus for public concern. ${ }^{1,2}$ The phenomenon of ED overcrowding cannot be attributed to any single factor ${ }^{1}$ but instead appears to be a product of complex causal relations, encompassing several internal and external factors, ${ }^{1,3,4}$ most of which are beyond the control of ED staff. ${ }^{4}$ Possible causes include use of the ED for non-emergent cases, ${ }^{5,6}$ an aging population, ${ }^{1}$ increasing patient acuity, ${ }^{4}$ labour shortages ${ }^{1,4}$ lack of community-based alternatives to the $\mathrm{ED},{ }^{1}$ delays while waiting for laboratory testing to be completed, ${ }^{4}$ lack of public education regarding appropriate ED use and the range of services available in general practitioners' offices, ${ }^{1,7}$ lack of long-term care and other alternative settings, ${ }^{1}$ and lack of availability of ED or inpatient beds (or both).,2,4,8-12

In contrast to previous studies, which have investigated overcrowding issues within the context of a single $\mathrm{ED}^{1-4,9,11,12}$ or addressed specific causes of the problem ${ }^{8,9,11,13-15}$ (Predy G, Fraser-Lee N, Gardener K, Edwards J, Brown J, Truman C. Emergency room use for nonurgent medical conditions and the "after hours" accessibility of family physicians in the Capital Health Authority region; unpublished manuscript) we took a systems-based approach, using data from multiple sites within an integrated geographic health region. Such an integrated delivery system offers opportunities for solutions that span the continuum of care in both hospital and community settings. In a previous study (documented in 2 articles ${ }^{16,17}$ ) that examined a regionalized health system, patient movements through the ED were analyzed by means of audited data collected from forms, charts and information systems, but our study focused on staff and physician perspectives.

In a recent study of ED overcrowding, researchers identified numerous effects of this problem, including risk of poor outcomes, prolonged pain and suffering for some patients, long waiting times, patient dissatisfaction, more ambulance diversions, lower physician productivity and higher levels of frustration among medical staff. ${ }^{3}$ The problem's complexity hampers holistic understanding and development of system-wide solutions for integrated, evidence-based health care delivery. The primary intent of this study was to describe the perceptions of health care professionals and service providers regarding ED overcrowding, including definitions of overcrowding, perceived characteristics of an overcrowded ED and service pressures that result in overcrowding. Our secondary objective was to solicit suggestions of strategies that might help in reducing overcrowding and in setting priorities within the ED.

\section{Methods}

In this exploratory field study, we collected data by focus group interviews, a standard qualitative research strategy. ${ }^{18}$

\section{Setting}

The Capital Health Authority, in Edmonton, is one of Canada's largest integrated health regions, planning and delivering a broad range of health services to its 816000 residents and to many people from the northern regions of western Canada who are referred to Capital Health tertiary 
facilities (a referral population of 1.6 million). Capital Health has 6 hospital-based EDs and 1 ED in a community health centre. Two of the EDs are in tertiary care centres, and they handle the major trauma cases in the region. Capital Health also offers a 24-hour teletriage system to direct residents to appropriate health care services within the region. The region has numerous medicentres and physician offices; however, the hours of operation in these settings vary, with limited evening, overnight and weekend physician accessibility. Some physicians have recorded messages on their phone lines directing patients to use ED services after usual office hours (Predy G, Fraser-Lee N, Gardener K, Edwards J, Brown J, Truman C. Emergency room use for non-urgent medical conditions and the "after hours" accessibility of family physicians in the Capital Health Authority region; unpublished manuscript). Access to community laboratory services is also limited, as many community-based laboratories do not operate all day, every day. People needing laboratory services after hours may access these services by visiting an ED.

\section{Focus group composition}

We selected key informants for this focus group study to ensure that, collectively, the participants had knowledge of all aspects of emergency medicine, including operations and administration. A formal written invitation to staff at each ED location was delivered through the site managers. The invitation requested representatives from the following disciplines: nursing (2 from each ED), medicine (1), social work (1), allied health professions (1) and support services (2). The requested number of front-line staff and physicians volunteered at 6 of the 7 sites, with the participants at each site constituting a single focus group. Representatives were not available for all occupations at the seventh site, where an in-depth interview was conducted with 1 physician and 2 nurses. A seventh focus group was conducted with the patient care managers from all ED sites.

\section{Data collection}

Before each focus group took place, participants received printed materials, including an information letter, a consent form and the list of questions to be addressed. Participants were encouraged to discuss these questions with their colleagues and to share their colleagues' comments during the focus groups.

The moderator for the focus groups (who was not an employee of the Capital Health Authority and who had no vested interest in the problem of ED overcrowding) was chosen through a formal contracting procedure that emphasized prior experience and knowledge. In consultation with the research team, the moderator prepared a focus group guide to allow free-flowing discussion while ensuring that all topic areas of interest were covered.

A member of the research team (A.E. or A.A.) observed each 2-hour focus group and answered questions if the moderator needed clarification or background related to an issue raised by a participant. Each focus group was audio taped and transcribed for later review and analysis.

At the beginning of the first three focus groups, a sentence-completion exercise was used to identify participants' perceptions of the outcomes, results, functions and features of a "successful" ED, as well as to determine the characteristics that they felt a successful ED would avoid. Ideas generated in these early sessions were validated during discussions in later focus groups.

In this study we used the term "service pressures" in ascertaining the reasons for overcrowding. Participants were asked about various factors contributing to service pressures: patient characteristics, factors perceived to be rooted in the ED itself and factors thought to be external to the ED. Three additional specific questions were also asked: What is meant by "service pressures"? When are service pressures thought to occur? What strategies might help to reduce service pressures?

\section{Analysis}

Responses from the sentence-completion exercise were coded, entered into a database and tabulated to provide a "service-oriented" description of how participants would like to see a successful ED run. The content of the responses was sorted into thematic areas, and level of agreement was determined. Because there was strong agreement among most participants for all of the themes, the analysis concentrated on the identified service pressures, the interrelationships among these pressures and their outcomes. A schematic model of the findings (Fig. 1) was developed; it was validated by an advisory group, which included some patient care managers and emergency physicians. The moderator prepared and submitted a written report to the research team, which was used to assist with the preparation of this manuscript.

\section{Results}

\section{Service pressures defined by study group}

The study group consisted of 8 emergency physicians, 8 ED managers and 42 ED staff (including clinical nurses, allied health care professionals, social workers and support staff), representing all 7 emergency departments in the Capital Health Region. The participants defined service 


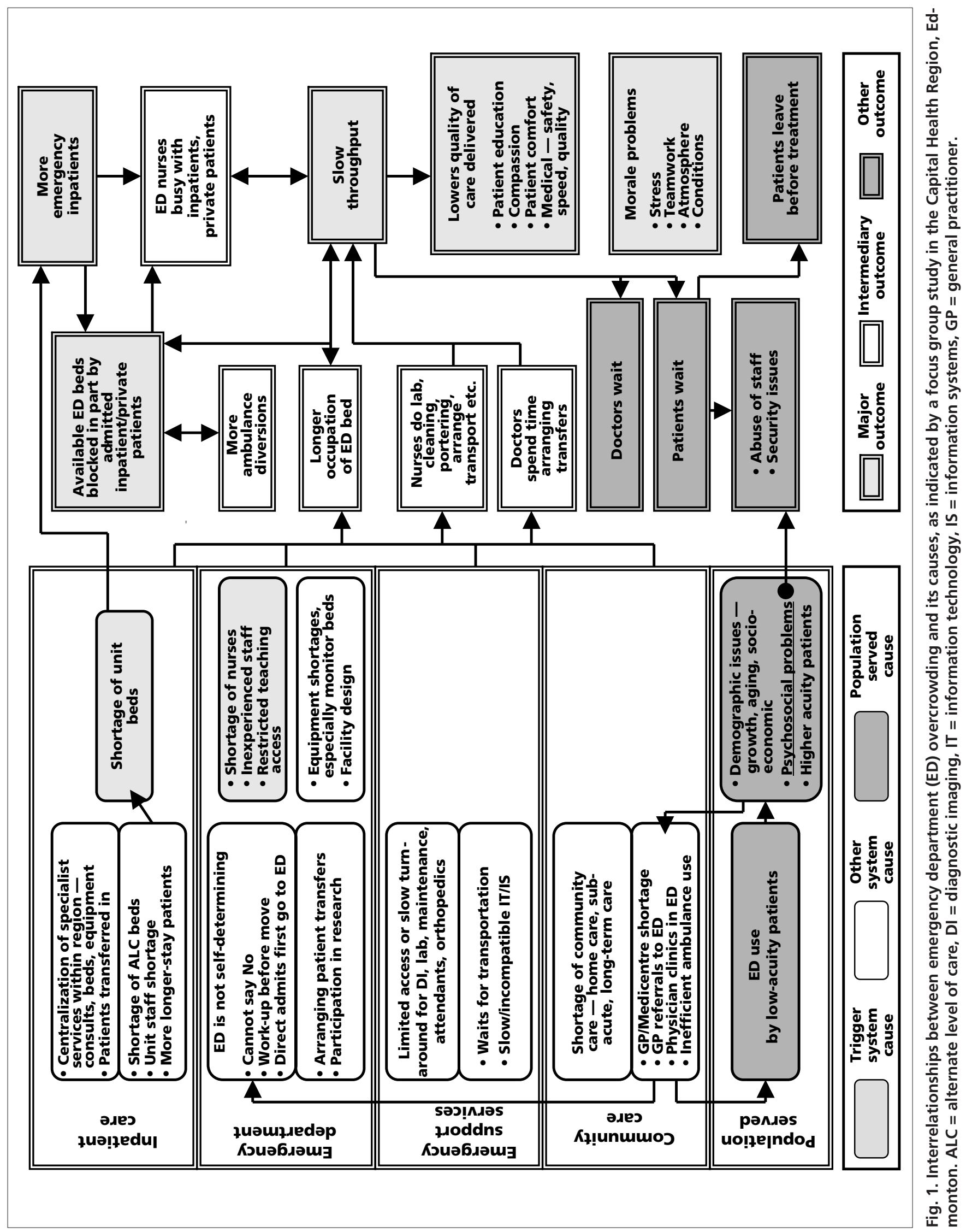


pressures as "anything that impedes the flow of patients through the ED, affects the quality of care delivered or results in patient frustration and/or stress to staff." This composite definition was derived from many individual definitions referring to specific factors such as delays in assessment, diagnosis and treatment, overtaxing of resources, inability to keep pace with demands for service, inability to provide quality care, and displays of dissatisfaction from patients and staff.

\section{Perceptions of when overcrowding occurs}

Overall, participants believed that overcrowding occurs frequently and that it can occur many times throughout a given day, and they identified certain times when overcrowding seemed more obvious. Some periods of increased activity are predictable, for example, during evenings and in winter. Others are less predictable, for example, after media reports of infectious disease outbreaks.

\section{Primary perceived causes of overcrowding}

Participants identified several causes that they believed impeded the flow of patients through the ED. We have attempted to capture diagrammatically these interrelationships between overcrowding and its causes (Fig. 1).

During each focus group, participants were asked to identify the most important causes of overcrowding. Managers and front-line staff believed that shortages of ED beds and of nursing staff were 2 key causes. Although the relative priority of these causes could not be determined because of the strong agreement among participants, this observation was supported by the results of the sentencecompletion exercise (Table 1). A theme that emerged from the identification of these key service pressures was a sense that the role of the ED is changing.

\section{Shortage of beds}

Participants perceived that the availability of ED stretchers for incoming patients was often severely limited because of admitted patients held in the ED while they waited for an available inpatient bed (admitted patients held). Participants believed that these admitted patients block ED stretchers, increase ED length of stay for all patients, and create additional workload for ED nurses. Participants attributed the high number of admitted patients held in the ED to a shortage of inpatient beds, which was in turn associated with shortages of floor nurses, high numbers of inpatients awaiting transfer to alternate levels of care and greater severity of illness among patients in the hospital as well as in the ED.

\section{Changing role of emergency departments}

Participants also believed that the shortage of inpatient beds has led to changing expectations regarding the role of the ED. The perception was that many non-emergency health care providers believe that EDs should function as holding units for the rest of the health care system. Partici-

Table 1. Responses to sentence-completion exercise

\begin{tabular}{|c|c|c|}
\hline \multirow{2}{*}{$\begin{array}{l}\text { A successful emergency department is not ... } \\
\text { Full or bogged down with admitted patients, medical } \\
\text { patients, ICU patients }\end{array}$} & \multicolumn{2}{|c|}{$\begin{array}{l}\text { No. }(\text { and } \%) \\
\text { of responses } \\
\quad(n=37)\end{array}$} \\
\hline & 16 & $(43)$ \\
\hline A stressful, pressured or high-stress environment & 10 & $(27)$ \\
\hline A holding unit for ALC or an LTC referral room & 9 & $(24)$ \\
\hline $\begin{array}{l}\text { A "dumping ground" for the health care system or a } \\
\text { safety net for the hospital }\end{array}$ & 7 & (19) \\
\hline A medicentre & 6 & $(16)$ \\
\hline $\begin{array}{l}\text { A referral centre for GPs who cannot find beds or obtain } \\
\text { consultations for their patients }\end{array}$ & 4 & $(11)$ \\
\hline $\begin{array}{l}\text { A personal clinic for consultants or for work-up of private } \\
\text { patients }\end{array}$ & 2 & (5) \\
\hline $\begin{array}{l}\text { A unit for direct admissions or admissions from other } \\
\text { facilities without beds }\end{array}$ & 2 & $(5)$ \\
\hline Always functioning to levels of overcapacity ("gridlock") & 2 & (5) \\
\hline A free-standing emergency room & 2 & (5) \\
\hline Other & 5 & $(14)$ \\
\hline
\end{tabular}


pants reported the expectation of staff elsewhere in the hospital that tests and paperwork should be completed before a patient is moved to an inpatient care unit, a practice that is perceived to extend the length of stay in the ED as patients wait for tests and test results.

\section{Staff shortages}

Participants also believed that a shortage of ED staff, especially nurses, contributed to overcrowding. Because of these shortages, nurses are asked to work a lot of overtime. Participants felt that limited availability of non-nursing members of the emergency team placed additional workload on nurses, particularly during peak times on evening and weekend shifts. They reported that nurses often perform tasks such as taking blood, cleaning, portering and arranging transport, in addition to their regular duties.

The burden of caring for admitted patients as well as emergency patients, and the requirement to juggle the requests of the physicians caring for these distinct patient groups, was said to present a difficult challenge. The pressure on nurses was increased by their feeling of discomfort in providing care to admitted patients under ED conditions.

Although staff shortages were identified primarily for nurses, shortages in other disciplines were also reported.

\section{Other perceived causes of overcrowding}

Participants stated that limited access to services such as home care, diagnostic imaging, laboratory services and social services resulted in longer ED stays. ED staff in most focus groups perceived that these support services did not have the same hours of service as the ED, and in particular that these services were not usually available during peak times such as weekends and holidays. Thus, patients stayed longer in ED beds while waiting for these services.

Access to specialist services was another concern. Participants commented that some community-based EDs did not have site-based specialty services (e.g., orthopedics, surgery, pediatrics and psychiatry). Instead, these services were centralized at the tertiary care sites, and ED staff had to coordinate patient transfers with staff at those other sites. Such transfers could be delayed if no beds were available at the receiving site. Participants reported frequent delays for patients awaiting ambulance transfers, which they believed resulted in "blocked beds."

Time devoted to teaching and research and delays resulting from slow or incompatible information systems were also of concern. The issue of low-acuity patients was one of the few on which perceptions were divided. Nursing staff, on the whole, preferred not to see such patients in the ED. However, some of the physicians felt that many ED visits coded as low-acuity (according to discharge diagnoses) were appropriate, because the final, low-acuity diagnosis was not apparent on presentation. Also, low-acuity visits provided a respite from caring for seriously ill patients. In contrast, all participants indicated that the increasing numbers of high-acuity elderly patients represented a concern.

\section{Interventions to help alleviate overcrowding}

Participants suggested many potential interventions to improve ED throughput and to address system-wide capacity.

Interventions proposed to improve throughput included increased availability of and quicker turnaround times for laboratory and diagnostic imaging services; sufficient availability of porters, laboratory technicians and other support staff; increased accessibility to community care and palliative care services; faster responses from and decisions by specialists; and determination of appropriate staffing levels.

Interventions proposed to improve system-wide capacity included establishing a holding unit for admitted patients or an observation unit adjacent to and managed by the ED, opening the outpatient department 24 hours a day, introducing an internal transportation service for transfers of patients between sites, and increasing acute and long-term bed capacity on the basis of patient need, taking into account the demands of EDs. Participants emphasized the importance of adequate funding and resources for EDs.

\section{Discussion}

The identified characteristics and causes of ED overcrowding were numerous. Two key problems were identified as causing many spin-off pressures: inefficient access to ED beds (stretchers) because of slow throughput of patients and staff shortages. The Canadian Association of Emergency Physicians ${ }^{19}$ and one international study ${ }^{3}$ have also identified these problems as major causes of overcrowding. The participants generally believed that the defining and causative factors could not be viewed independently; rather, in the search for remedies, they should be considered as interrelated variables.

\section{Characteristics of ED overcrowding}

We anticipated that ED staff might define service pressures on the basis of their feelings of stress, but this was not the case. The definition of service pressures arising from the focus groups was based on a perceived inability to achieve desired standards; this definition was key in identifying the causes of overcrowding. 
Overall, participants perceived overcrowding as a continuous feature of the ED, but they were able to identify daily and seasonal peaks. Winter peaks have been reported in a number of other North American and international studies $^{13,20,21}$ (Predy G, Fraser-Lee N, Gardener K, Edwards J, Brown J, Truman C. Emergency room use for non-urgent medical conditions and the "after hours" accessibility of family physicians in the Capital Health Authority region; unpublished manuscript).

\section{Causes of ED overcrowding}

Perceived changes in the role of the ED were discussed during the focus groups. In particular, nurses talked about the new roles that they have had to assume over time; for example, care of admitted patients is now a regular nursing function within the ED. Whether such functions are appropriate for the ED must be determined by health care policy-makers as they define the future role of EDs in the health care system.

\section{Potential solutions to ED overcrowding}

Participants proposed several interventions to improve ED throughput, including increasing staff and ED beds and providing greater access to support services. However, these solutions address the causative factors superficially and independently, without considering the interrelationships among them; thus, they would provide only short-term relief. For example, increasing the number of ED staff could increase throughput, but only so long as beds are available for new patients. Increasing ED bed capacity would not increase throughput if nurses were already too busy with other duties, including care of admitted patients. However, the existence of interrelationships does not mean that these specific problems should be disregarded. Instead, they could be addressed within a systematic plan that considers capacity throughout the continuum of care and that redefines the role of the $\mathrm{ED}$ in a regional health care system.

Other researchers have suggested ways of reducing ED overcrowding. ${ }^{12,14}$ However, we found few primary studies evaluating the effectiveness of such interventions. Derlet and associates ${ }^{15}$ concluded that patients for whom ED care was deemed unnecessary could be redirected from the ED without significant adverse outcomes. Studies by Kyriacou and colleagues ${ }^{9}$ and Hadjistavropoulos and collaborators $^{16,17}$ have illustrated the difficulty of reducing ED length of stay under conditions of fiscal restraint. One Canadian study found that an ED observation unit would be difficult to justify given the small number of patients who would benefit. ${ }^{22}$ It is likely that many of the recommendations suggested by participants in this study have been tried in other jurisdictions, but the results have remained unpublished. Promising interventions could be implemented at pilot sites and evaluated objectively before full implementation at the regional level.

One of the challenges in implementing any set of solutions is the absence of national standards to guide planning and delivery of ED services in Canada. This makes it difficult to determine fundamental requirements such as the acceptable number of ED beds per capita, acceptable waiting times for admitted patients and acceptable staffing ratios. Lenehan $^{8}$ reported that ED nurse managers across the United States were struggling to create systems that would collect data that could be used in setting basic ED staffing levels. Clearly, national standards for emergency care must be developed and monitored.

\section{Strengths and limitations}

The focus group process was a convenient and insightful way to gain an in-depth understanding of the perceived causes of overcrowding. Information provided by participants gave the research team a richer appreciation of the context and complexity of the situation. Because focus group findings are based on perceptions, they should be validated at individual sites with quantitative data before interventions are designed and implemented. These study findings enabled the team to better prioritize areas for such validation.

The study results are limited because respondents were not selected randomly and their opinions may not represent those of all ED staff. Furthermore, although the intent was to allow sufficient time for all participants to answer all of the questions posed, some participants may not have had enough time to make suggestions on potential interventions.

\section{Conclusions}

The perceptions of health care professionals and service providers indicate that ED overcrowding is a complex issue that requires a system-based plan of action. Qualitative research such as that reported here can, through appropriate formulation of questions and systematic collection of data, identify and describe complex interactions in realworld settings. ${ }^{18}$ The findings of such studies can lead to quantitative studies involving objective measurement.

Competing interests: None declared.

\section{References}

1. Van de Bogart L. Crisis in the emergency department: contributing factors and potential solutions. In: Hallway medicine. Toronto: Insight Press; 2000.

2. Feferman I, Cornell C. How we solved the overcrowding prob- 
lem in our emergency department. CMAJ 1989;140:273-6.

3. Derlet R, Richards J. Overcrowding in the nation's emergency departments: complex causes and disturbing effects. Ann Emerg Med 2000;35(1):83-5.

4. Richards J, Navarro M, Derlet R. Survey of directors of emergency departments in California on overcrowding. West J Med 2000;172(6):385-8.

5. Richardson SK. Increasing patient numbers: the implications for New Zealand emergency departments. Accid Emerg Nurs 1999;7(3):158-63.

6. Coast J, Ingles A, Franked S. Alternatives to hospital care: What are they and who should decide? BMJ 1996;312:162-6.

7. Boushy D, Dubinsky I. Primary care physician and patient factors that result in patients seeking emergency care in a hospital setting: the patient's perspective. J Emerg Med 1999;17(3):405-12.

8. Lenehan GP. ED short staffing: It is time to take a hard look at a growing problem and strategies such as standard nurse-patient ratios. J Emerg Nurs 1999;25(2):77-8.

9. Kyriacou D, Ricketts V, Dyne P, McCollough M, Talan D. A 5year study analysis of emergency department patient care efficiency. Ann Emerg Med 1999;34(3):326-35.

10. Wardrope J, Kidner N, Edhouse J. Bed crises are occurring almost daily in some hospitals. BMJ 1995;310:868-9.

11. Fromm RE Jr, Gibbs LR, McCallum WG, Niziol C, Babcock JC, Gueler AC, et al. Critical care in the emergency department: a time based study. Crit Care Med 1993;21(7):970-6.

12. Lynn S, Kellermann A. Critical decision making: managing the emergency department in an overcrowded hospital. Ann Emerg Med 1991;20:287-92.

13. Mythbusters series. Myth no. 1: More money would put an end to emergency room crunches. Ottawa: Canadian Health Services Research Foundation; 2000. Available: www.chsrf.ca/docs /resource/myth1_e.pdf (accessed 2003 Feb 6).

14. Conn AD, Shimkus GV, Inbornone R. Eyeing the ED's open door: how case managers can reduce unnecessary admissions. Dimens Crit Care Nurs 2000;19(2):35-6.

15. Derlet RW, Nishio D, Cole LM, Silva J Jr. Triage of patients out of the emergency department: three-year experience. Am J Emerg Med 1992;10(3):195-9.

16. Hadjistavropoulos H, Clark J, Hardenne D, Lochbaum B, Larrivee D. Use of an ER audit to build recommendations for improving quality of care. Part I: Initial audit and recommendations. Healthc Manage Forum 2000;13(2):49-53.

17. Hadjistavropoulos H, Clark J, Hardenne D, Lochbaum B, Larrivee D. Use of an ER audit to build recommendations for improving quality of care. Part II: Follow-up to an ER study. Healthc Manage Forum 2000;13(2):54-7.

18. Marshall C, Rossman GB. Designing qualitative research. 2nd ed. Thousand Oaks (CA): Sage Publications; 1995.

19. Canadian Association of Emergency Physicians, National Emergency Nurses Affiliation. Joint Position Statement on emergency department overcrowding. CJEM 2001;3(2):82-4.
20. Hider P, Helliwell P, Ardagh M, Kirk R. The epidemiology of emergency department attendances in Christchurch. N Z Med J 2001;114(1129):157-9.

21. Menec VH, Roos NP, Nowicki DL, MacWilliam L, Finlayson G, Black C. Seasonal patterns of Winnipeg hospital use. Winnipeg: Manitoba Centre for Health Policy and Evaluation; 1999 Oct.

22. Sinclair D, Green R. Emergency department observation unit: Can it be funded through reduced inpatient admission? Ann Emerg Med 1998;32(6):670-5.

Correspondence to: Angela Estey, Regional Planner, Clinical Performance Information \& Research, Capital Health, 9th floor, 9925109 St., Edmonton AB T5K 2J8; 780 413-7742; AEstey@cha.ab.ca
$1 / 4$ page $b / w$

repeat of Sept 2002 / p.330 